Research

\title{
Pituitary-adrenal function in patients with acute subarachnoid haemorrhage: a prospective cohort study
}

\author{
Stepani Bendel'1, Timo Koivisto², Esko Ruokonen ${ }^{1}$, Jaakko Rinne², Jarkko Romppanen ${ }^{3}$, \\ Ilkka Vauhkonen ${ }^{4}$, Vesa Kiviniemi ${ }^{5}$ and Ari Uusaro ${ }^{1}$
}

\author{
1Department of Intensive Care, Kuopio University Hospital and Kuopio University, Puijonlaaksontie 2, 70211 Kuopio, Finland \\ ${ }^{2}$ Department of Neurosurgery, Kuopio University Hospital, Puijonlaaksontie 2, 70211 Kuopio, Finland \\ ${ }^{3}$ Eastern Finland Laboratory Centre, Kuopio University Hospital, Puijonlaaksontie 2, 70211 Kuopio, Finland \\ ${ }^{4}$ Department of Medicine, Kuopio University Hospital and Kuopio University, Puijonlaaksontie 2, 70211 Kuopio, Finland \\ 5IT Centre, Kuopio University PO Box 1627, 70211, Finland
}

Corresponding author: Stepani Bendel, Stepani.Bendel@kuh.fi

Received: 24 Jun 2008 Revisions requested: 14 Jul 2008 Revisions received: 30 Aug 2008 Accepted: 13 Oct 2008 Published: 13 Oct 2008

Critical Care 2008, 12:R126 (doi:10.1186/cc7084)

This article is online at: http://ccforum.com/content/12/5/R126

(c) 2008 Bendel et al.; licensee BioMed Central Ltd.

This is an open access article distributed under the terms of the Creative Commons Attribution License (http://creativecommons.org/licenses/by/2.0), which permits unrestricted use, distribution, and reproduction in any medium, provided the original work is properly cited.

\begin{abstract}
Introduction Subarachnoid haemorrhage (SAH) may damage the hypothalamo-pituitary-adrenal gland (HPA) axis and disturb cortisol metabolism. There are no available data that relates to the response of the HPA axis in the acute phase of SAH. We aimed to characterise the behavior of serum adrenocorticotropic hormone $(\mathrm{ACTH})$, total cortisol, stimulated total cortisol and free cortisol concentrations in acute aneurysmal $\mathrm{SAH}$.
\end{abstract}

Methods A prospective cohort study was conducted of patients with acute aneurysmal SAH $(n=30)$ admitted to a tertiary university hospital. Patients admitted for elective aneurysmal surgery $(n=16)$ served as the control group. An ACTH stimulation test was performed twice during the first week and at three months. The main outcome measure was description of the $\mathrm{ACTH}$-cortisol response by calculating serum free cortisol and measuring total cortisol and ACTH concentrations. A mixed models method was used for testing between the groups, allowing heterogeneity between the groups.

Results Patients with SAH had higher initial serum total cortisol (mean +/- SD; 793 +/- $312 \mathrm{nmol} / \mathrm{L}$ ) and free cortisol concentrations $(83+/-55 \mathrm{nmol} / \mathrm{L})$ than control patients $(535+/$
- $193 \mathrm{nmol} / \mathrm{L}, \mathrm{p}=0.001$ and $33+/-18 \mathrm{nmol} / \mathrm{L}, \mathrm{p}<0.001$, respectively). Thereafter, there were no differences in this respect. Serum free and total cortisol concentrations correlated but were unaffected by the severity of SAH. ACTH concentrations were comparable between SAH and control groups. Patients with Hunt-Hess grades IV to $\mathrm{V}$ had higher ACTH concentrations at day one $(10.7+/-7.1 \mathrm{pmol} / \mathrm{I} / \mathrm{L})$ and day five $(8.2+/-7.7 \mathrm{pmol} / \mathrm{L})$ than patients with grade I-III (day one: $3.8+/-2.0 \mathrm{pmol} / \mathrm{L}, \mathrm{p}=0.002$; day five: $4.7+/-1.8 \mathrm{pmol} / \mathrm{L}, \mathrm{p}=$ $0.04)$.

Conclusions Calculation of serum free cortisol concentration was not helpful in identifying patients with potential hypocortisolism. SAH severity did not affect cortisol concentrations, possibly indicating relative pituitary-adrenal insufficiency in patients with more severe bleeding.

Trial registration ClinicalTrials.gov Identifier NCT00614887.

\section{Introduction}

Recent studies suggest that disturbed glucocorticoid metabolism and adrenal insufficiency may adversely affect outcome in patients with subarachnoid haemorrhage (SAH) and traumatic brain injury (TBI) [1-5]. There is some evidence of a high incidence of delayed adrenal insufficiency (AI) in patients with SAH [5-7]. Most studies, however, have focused on TBI, and there are almost no data on the function of the hypothalamopituitary-adrenal gland (HPA) axis in patients with acute $\mathrm{SAH}$.

ACTH: adrenocorticotropic hormone; Al: adrenal insufficiency; CBG: corticosteroid binding globulin; GCS: Glascow Coma Scale; HDU: highdependency unit; HPA: hypothalamo-pituitary-adrenal; ICU: intensive care unit; LOS: length of stay; SAH: subarachnoid haemorrhage; SD: standard deviation; TBI: traumatic brain injury. 
In patients with SAH, the HPA axis may be affected by direct compression of the hypothalamus or pituitary gland by an aneurysm and/or blood clot. In addition, elevated intracranial pressure, vasospasm, microinfarctions of the pituitary gland, venous stasis or surgical procedures may injure these structures [8]. There is no definition of adequate HPA response in patients with SAH. For example, cut-off values for Al in patients with SAH have been derived from other patient populations, and therefore these values may not be valid in patients with $\mathrm{SAH}$. Furthermore, the previous studies have focused on a single time point after $\mathrm{SAH}$, and the function of the HPA axis over time has not been investigated. The relationship between serum free versus total cortisol concentrations is also not known in these patients [8].

The aim of our study was to characterise the function of the HPA axis acutely and over time for up to three months in patients with SAH. We used various methods, including serum free cortisol calculation and measurement of serum total cortisol concentration. We also performed testing of adrenocorticotropic hormone (ACTH) and measured ACTH concentrations over time.

\section{Materials and methods}

All patients aged 18 years and older who were scheduled for elective surgical aneurysm treatment (control group) and all patients with SAH admitted to the Kuopio University Hospital in Finland between 29 March and 30 November, 2006, were prospectively assessed for eligibility for this study. The exclusion criteria for the study were any corticoid treatment (including inhaled), use of etomidate before study entry or during the study period, unknown exact bleeding day, previous history of $\mathrm{SAH}$, bleeding from more than three days before inclusion, traumatic $\mathrm{SAH}$, known pituitary insufficiency, and/or a moribund state of the patient. Only surgical patients were enrolled into the control group because the prescheduled hospital stay for patients with embolised aneurysms was too short. The hospital ethics committee approved the study protocol, and informed written consent was received from the patients or their next of kin.

\section{Patients with subarchnoid haemorrhage}

The following blood samples were collected from the first to the seventh morning after bleeding: serum (s) cortisol (reference value $=170$ to $540 \mathrm{nmol} / \mathrm{L}$ ), s-corticoid-binding globulin (s-CBG) (reference value male $=22$ to $55 \mu \mathrm{g} / \mathrm{L}$; reference value female $=40$ to $154 \mu \mathrm{g} / \mathrm{L}$ ) and $\mathrm{s}$-albumin (reference value $=36$ to $45 \mathrm{~g} / \mathrm{L}$ ). Also, samples for $\mathrm{ACTH}$ analysis (reference value $=0$ to $11 \mathrm{pmol} / \mathrm{L}$ ) were collected on the first and seventh days. An ACTH-stimulating test $(250 \mu \mathrm{g}$ of tetracosactide (Synachten, Ciba-Geigy, France) administered intravenously) was performed on the first morning in the intensive care unit (ICU) and seven days after the bleeding. On the second and sixth days in the ICU, 24-hour urinary cortisol excretion (reference value $=100$ to $380 \mathrm{nmol}$ ) was measured.

\section{Control patients}

Blood samples were collected from control patients that were equivalent to those collected from the patients with $\mathrm{SAH}$. The second ACTH sample was collected on day five. The first cortisol samples were drawn and an ACTH test was performed on day one before surgery and on day five postoperatively, and then patients were discharged. On day two, 24-hour urinary cortisol excretion was measured.

\section{Follow up at three months}

At the scheduled three-month follow-up visit, serum total cortisol concentration was measured and free cortisol concentration was calculated at $9 \mathrm{am}$, followed by an ACTH-stimulation test performed in both groups.

Samples for serum free cortisol calculation were stored at $70^{\circ} \mathrm{C}$ for later analysis. The same personnel performed all analyses in one laboratory at the Kuopio University Hospital. We used electrochemiluminescence immunoassay (Elecsys Cortisol, Roche Diagnostics, Mannheim, Germany) as the diagnostic method. The Coolens method was used to calculate serum free cortisol concentration [9]: $U^{2} K(1+N)+U[1+N+K(G$ - $T$ )] $-T=0$, where $K=3 \times 10^{-7} \mathrm{M}^{-1}$ (affinity of CBG) to cortisol at $37^{\circ} \mathrm{C}, \mathrm{G}=\mathrm{CBG}, U=$ unbound cortisol, $T=$ cortisol, and $N$ $=$ ratio of albumin bound to free cortisol (1.74). $U$ was calcu-

lated as follows: $\quad U=\sqrt{Z^{2}+\frac{T}{(1+N) K}}-Z$, where

$Z=\frac{1}{2 K}+\frac{G-T}{2(1+N)}$

Serum CBG concentrations were analysed with radioimmunoassay (BioSource Europe S.A., Nivelles, Belgium). After dichloromethane extraction, urinary free cortisol concentrations were analysed using the same method employed for serum total cortisol measurement. Plasma ACTH concentrations were analysed using an immunoluminometric assay (IMMULITE; Diagnostic Products Corporation, Los Angeles, $\mathrm{CA})$.

Several serum cortisol concentration cut-off values for Al have been published. We used a random serum total cortisol concentration of less than $500 \mathrm{nmol} / \mathrm{L}$ to indicate $\mathrm{Al}[10,11]$. For free cortisol, we used a concentration of less than $55 \mathrm{nmol} / \mathrm{L}$ as the cut-off for risk of $\mathrm{Al}$ [12]. We also tried to find out patients from our study population with low serum total (less than $350 \mathrm{nmol} / \mathrm{L}$ ) and/or free cortisol concentrations (less than $22 \mathrm{nmol} / \mathrm{L}$ ) and low serum ACTH concentrations (less than $5 \mathrm{pmol} / \mathrm{L}$ ) to search for those at risk of secondary Al [11].

In addition, a total cortisol response less than $248 \mathrm{nmol} / \mathrm{L}$ to exogenous $250 \mu \mathrm{g} \mathrm{ACTH} \mathrm{[13]} \mathrm{was} \mathrm{used} \mathrm{as} \mathrm{a} \mathrm{marker} \mathrm{for} \mathrm{rela-}$ tive Al. 
(a)

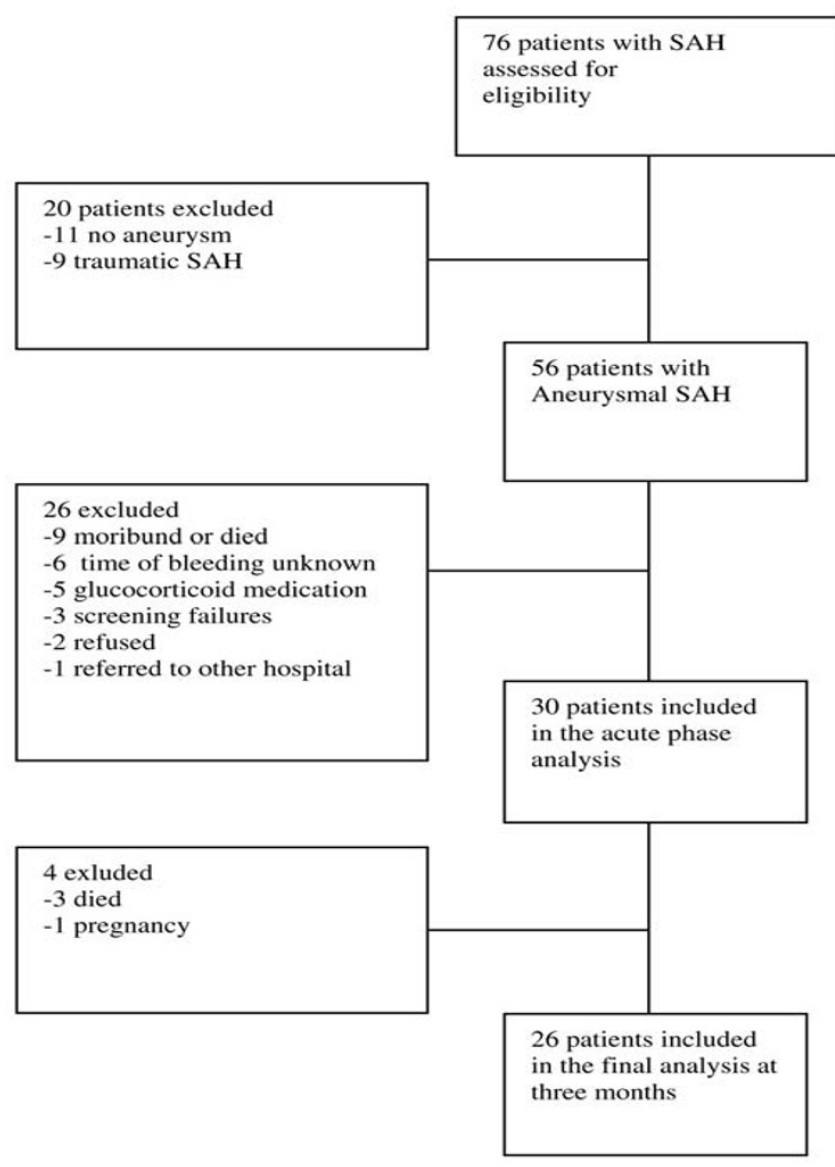

(b)

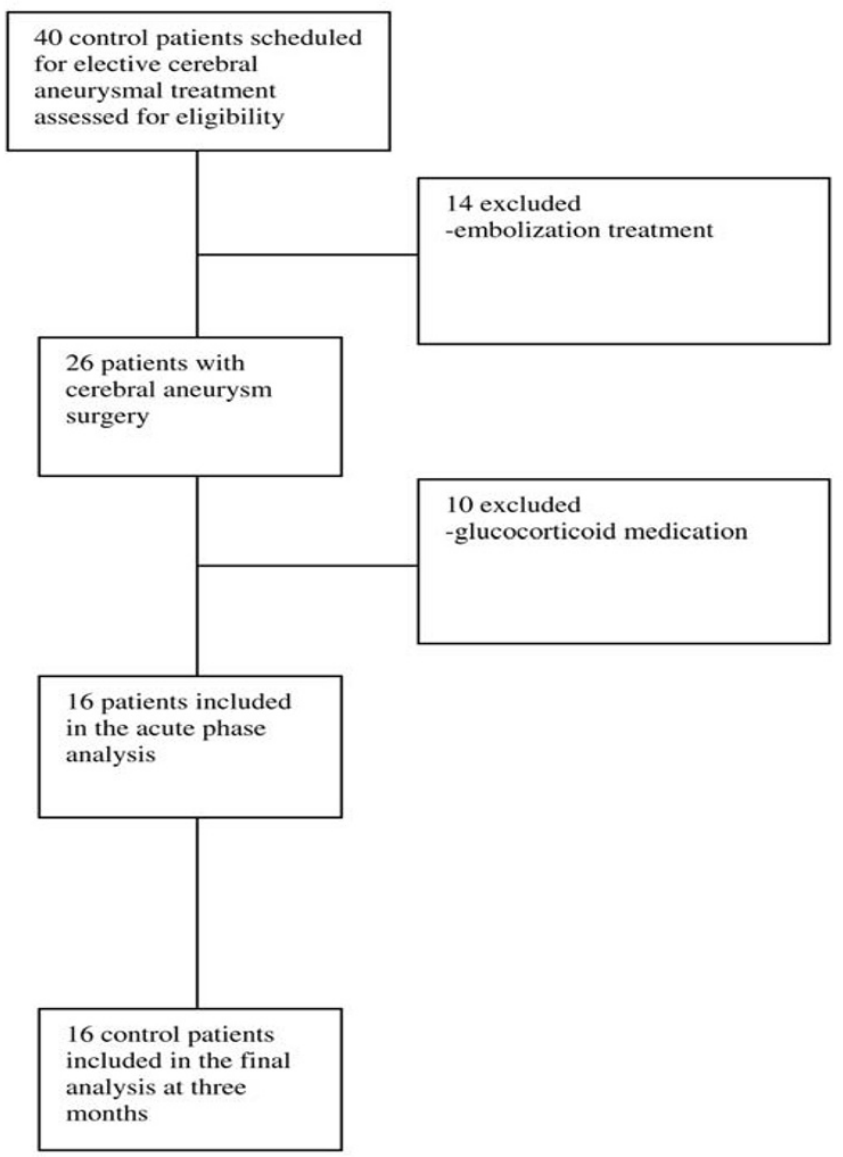

Flow chart of patients with (a) subarchnoid haemorrhage (SAH) and (b) control patients.

\section{Statistical methods}

We used a power of $80 \%$ and a two-sided $\alpha$-level of 0.05 in sample size calculations. We assumed that $25 \%$ of patients with $\mathrm{SAH}$ and none of the elective surgical patients would develop AI [14], and decided to recruit 30 patients with SAH and 30 control patients.

Data are presented as mean \pm standard deviation (SD) or as absolute values and percentages or medians and interquartile ranges. Distribution of the parameters was assessed by the Kolmogorov-Smirnov test. For normally distributed parameters, student's $t$-tests were used to compare the means of different groups. The Mann-Whitney $U$ test was used for nonparametric testing between the groups. A mixed models method was used for testing between the groups, allowing heterogeneity between the groups.
Spearman or Pearson correlations were calculated. SPSS 14.0 software (SPSS, Chicago, IL) was used to perform the analyses.

\section{Results}

Thirty patients with $\mathrm{SAH}$ and 16 control patients assessed for elective cerebral aneurysm operations were enrolled into the study (Figures 1a and 1b). Recruitment was very slow because of the frequent choice of endovascular aneurysm treatment and high rate of exclusion for other reasons, and we were unable to enroll the planned 30 surgical patients into the control group. Seventeen patients with SAH underwent endovascular treatment and 13 patients had open surgery. The mean length of stay (LOS) for patients with SAH was 97 \pm 100 hours at the ICU and $34 \pm 51$ hours at the high-dependency unit (HDU). Patients in the control group had an LOS in the HDU of $22 \pm 2$ hours. Patients with SAH had a hospital LOS of $14.6 \pm 5.4$ days and patients in the control group had a hospital LOS of $8 \pm 3$ days $(p<0.001)$. The three-month 
mortality was $10 \%$ in patients with $\mathrm{SAH}$ and none of the patients in the control group died. Demographic data for the patients are presented in Table 1.

Serum total and free cortisol concentrations are presented in Figure 2. In the control patients, the mean random serum total cortisol concentrations were $535 \pm 193 \mathrm{nmol} / \mathrm{L}$ at day one, $666 \pm 244 \mathrm{nmol} / \mathrm{L}$ at day two, $571 \pm 224 \mathrm{nmol} / \mathrm{L}$ at day three, $641 \pm 261 \mathrm{nmol} / \mathrm{L}$ at day four, $534 \pm 178 \mathrm{nmol} / \mathrm{L}$ at day five and $517 \pm 185 \mathrm{nmol} / \mathrm{L}$ at three months. The mean random serum free cortisol concentrations were $33 \pm 18 \mathrm{nmol} / \mathrm{L}$ at day one, $61 \pm 48 \mathrm{nmol} / \mathrm{l}$ at day two, $46 \pm 33 \mathrm{nmol} / \mathrm{L}$ at day three, $49 \pm 36 \mathrm{nmol} / \mathrm{L}$ at day four, $34 \pm 18 \mathrm{nmol} / \mathrm{L}$ at day five and 31 $\pm 17 \mathrm{nmol} / \mathrm{l}$ at three months.

In the patients with $\mathrm{SAH}$, the mean random serum total cortisol concentrations were $793 \pm 312 \mathrm{nmol} / \mathrm{L}$ at day one, $736 \pm 320$ $\mathrm{nmol} / \mathrm{L}$ at day two, $679 \pm 271 \mathrm{nmol} / \mathrm{L}$ at day three, $620 \pm 258$ $\mathrm{nmol} / \mathrm{L}$ at day four, $596 \pm 262 \mathrm{nmol} / \mathrm{L}$ at day five and $454 \pm$ $124 \mathrm{nmol} / \mathrm{L}$ at three months. The mean random serum free cortisol concentrations were $83 \pm 55 \mathrm{nmol} / \mathrm{L}$ at day one, $74 \pm 57$ $\mathrm{nmol} / \mathrm{L}$ at day two, $63 \pm 44 \mathrm{nmol} / \mathrm{L}$ at day three, $44 \pm 24 \mathrm{nmol} /$ $L$ at day four, $46 \pm 40 \mathrm{nmol} / \mathrm{l}$ at day five and $24 \pm 9 \mathrm{nmol} / \mathrm{L}$ at three months.

The dependence of free cortisol on total cortisol (Figure 3) shows the expected hyperbolic increase of free cortisol with total cortisol, until CBG is saturated, when the relation becomes linear. There was a good correlation between serum total and free cortisol concentration at day one $(r=0.66, p<$ $0.001)$, day three $(r=0.9, p<0.001)$, day five $(r=0.886, p<$ $0.001)$ and three months $(r=0.75, p<0.001)$ (Figure 3$)$.

The percentages of patients whose serum total cortisol concentration was less than $500 \mathrm{nmol} / \mathrm{L}$ or with a serum free cortisol concentration less than $55 \mathrm{nmol} / \mathrm{L}$ are presented in Figure 4.

There was a significant difference between control patients and patients with $\mathrm{SAH}$ at day one in serum total $(p=0.001)$ and free $(p=0.001)$ cortisol concentrations. There was no dif-

Table 1

\section{Demographic data of the patients}

\begin{tabular}{|c|c|c|c|}
\hline & $\mathrm{SAH}(\mathrm{n}=30)$ & Control $(n=16)$ & $p$ value \\
\hline Age, years (range) & 52 (21 to 78 ) & 50 (37 to 64$)$ & 0.53 \\
\hline Gender M/F & $14 / 16$ & $4 / 12$ & 0.15 \\
\hline \multicolumn{4}{|l|}{ Aneurysm location } \\
\hline ICA & 6 & 6 & \\
\hline MCA & 8 & 10 & \\
\hline$A c o A$ & 11 & 0 & \\
\hline ACA distal & 2 & 0 & \\
\hline VBA & 3 & 0 & \\
\hline Hydrocephalus at admission & 6 & 0 & \\
\hline \multicolumn{4}{|l|}{ Fisher grade ${ }^{16}$} \\
\hline I to II & 4 & & \\
\hline III to IV & 26 & & \\
\hline \multicolumn{4}{|l|}{ Hunt-Hess initial ${ }^{15}$} \\
\hline I to || & 15 & & \\
\hline III & 6 & & \\
\hline IV to $\mathrm{V}$ & 9 & & \\
\hline SAPS II & $30 \pm 13$ & & \\
\hline APACHE II & $15 \pm 6$ & & \\
\hline
\end{tabular}

Data are presented as numbers or mean \pm standard deviation unless otherwise indicated. $\mathrm{ACA}=$ anterior cerebral artery; AcoA $=$ anterior communicating artery; APACHE = Acute Physiology and Chronic Health Evaluation; HDU = high dependency unit; ICA = internal carotid artery; $\mathrm{ICU}=$ intensive care unit; LOS = length of stay; MCA = median cerebral artery; SAH = subarachnoid haemorrhage; SAPS = Simplified Acute Physiology Score. VBA = vertebro basilar artery. 
(a)

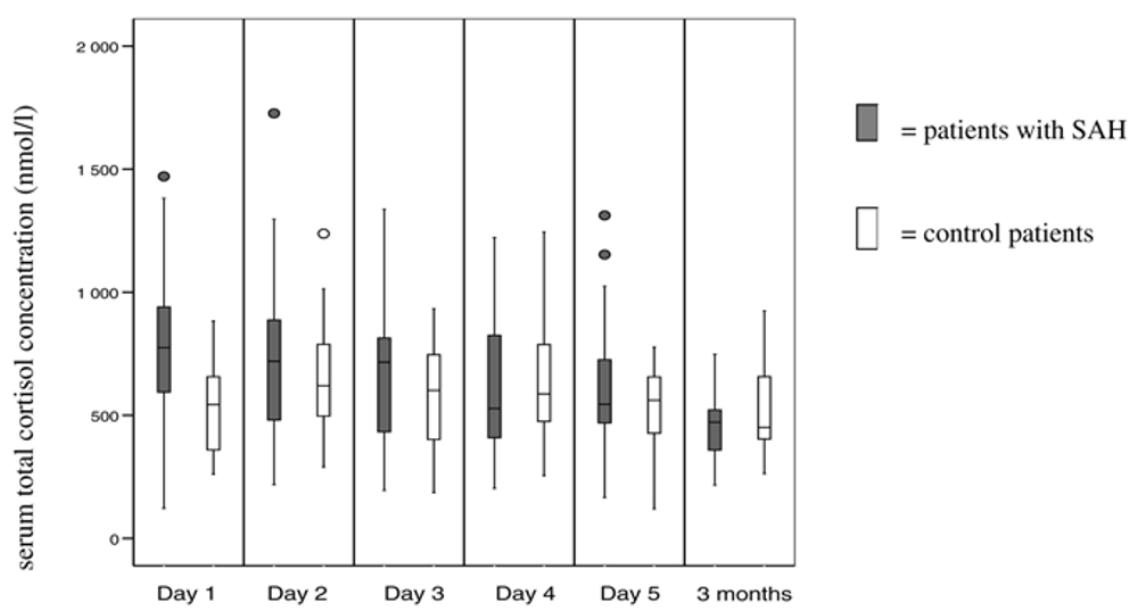

(b)

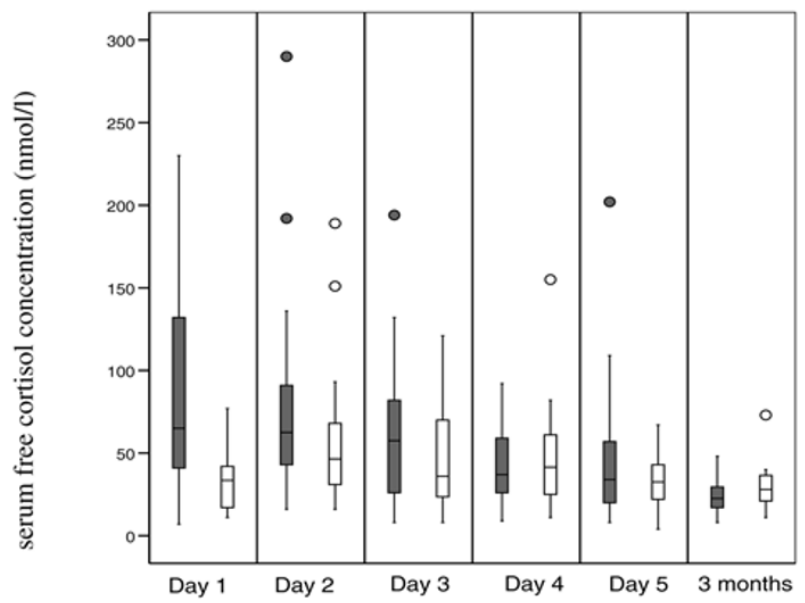

Serum free and total cortisol concentrations. Patients with subarchnoid haemorrhage $(\mathrm{SAH})$ had higher initial (a) serum total cortisol $(p=0.001)$ and $(b)$ free cortisol concentrations $(p<0.001)$ than control patients. At later time points, there were no differences between the groups in this respect. Data are presented as median, interquartile ranges and outliers.

ference in serum total or free cortisol concentrations through the study period in patients with $\mathrm{SAH}$ divided into groups with GCS at the first 24 hours of less than eight $(n=9)$ or more than eight. The cortisol concentrations also did not differ between patients who required $(n=9)$ or did not require noradrenaline due to symptomatic vasospasm and/or cerebral perfusion pressure maintenance. Hydrocephalus at admission $(n=6)$ or hypoalbuminea $(<25 \mathrm{~g} / \mathrm{L})(\mathrm{n}=8)$ did not affect serum free or total cortisol concentrations in patients with $\mathrm{SAH}$. In addition, patients with $\mathrm{SAH}$ and a serum albumin of either less than $25 \mathrm{~g} / \mathrm{L}$ or more than $25 \mathrm{~g} / \mathrm{L}$ had equal free/ total cortisol concentration ratios. Bleeding severity according to Hunt-Hess grade [15] did not affect serum free or total cor- tisol concentrations. There was neither any difference in the serum free or total cortisol concentrations if the patients had hyponatraemia ( $p$-natrium $<130 \mathrm{mmol} / \mathrm{L}$ ) at any time during the study. No patient had sepsis. Control patients received cloxacillin twice at the first day. Patients with $\mathrm{SAH}$ received cloxacillin for prophylaxis if they had intraventricular pressure monitoring.

At day one, patients with SAH had an ACTH concentration of $5.3 \pm 4.7 \mathrm{pmol} / \mathrm{L}$; in the control patients, the concentration was $4.4 \pm 2.2 \mathrm{pmol} / / \mathrm{L}(\mathrm{p}=0.88)$. At day seven, the ACTH concentration was $5.6 \pm 4.2 \mathrm{pmol} / \mathrm{L}$ in patients with $\mathrm{SAH}$ and $4.4 \pm 1.3 \mathrm{pmol} / \mathrm{L}$ at day five in the control group $(p=0.43)$. 
Figure 3

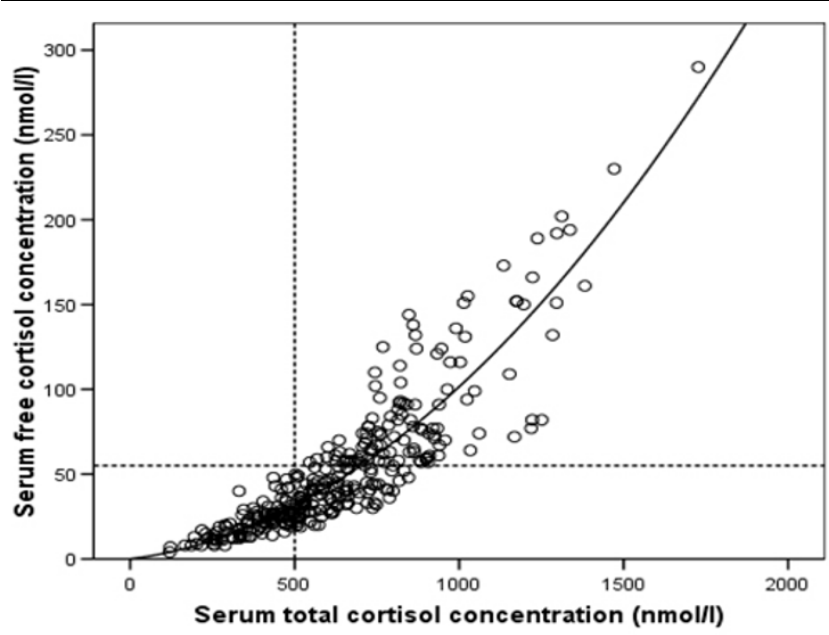

Pooled data and quadratic regression analysis. Equation from quadratic regression analysis for serum free cortisol concentration $=0.024$ $\times$ serum total cortisol concentration $+0.0000772 \times$ total cortisol concentration ${ }^{2}$. Pearson correlation coefficient $0.88, p<0.001$.

Serum ACTH correlated with serum free cortisol concentration at day one $(r=0.32, p=0.045)$. Otherwise serum total or free cortisol concentrations did not correlate with serum ACTH concentration. There were two patients with $\mathrm{SAH}$ who had low serum total cortisol concentrations $(122 \mathrm{nmol} / \mathrm{L}$ and $303 \mathrm{nmol} / \mathrm{L}$ ) and low serum free cortisol concentrations (7 $\mathrm{nmol} / \mathrm{L}$ and $21 \mathrm{nmol} / \mathrm{L})$ combined with low ACTH concentrations (3.08 pmol/L and $2.2 \mathrm{pmol} / \mathrm{L})$ at the first day: they both had normal values afterwards. The other patient of these two also failed the three-month ACTH test (ACTHresponse $<248 \mathrm{nmol} / \mathrm{l})$.

After one week there were two patients with low serum total cortisol concentrations ( $254 \mathrm{nmol} / \mathrm{L}$ and $335 \mathrm{nmol} / \mathrm{L}$ ) and low serum free cortisol concentrations ( $14 \mathrm{nmol} / \mathrm{L}$ and $14 \mathrm{nmol} / \mathrm{L})$ with a combination of low serum ACTH concentrations (2.64 $\mathrm{pmol} / \mathrm{L}$ and $2.2 \mathrm{pmol} / \mathrm{L})$. Additionally there were two patients with isolated low serum free cortisol concentrations $(20 \mathrm{nmol} /$ $\mathrm{L}$ and $21 \mathrm{nmol} / \mathrm{L}$ ) and normal total cortisol concentrations (573 nmol/L and $474 \mathrm{nmol} / \mathrm{L}$ ) but low ACTH concentrations (4.4 pmol/L and $3.5 \mathrm{pmol} / \mathrm{L})$.

Treatment modality or aneurysm location (anterior communicating artery versus other artery) did not affect serum ACTH or free or total cortisol concentrations. Patients with Hunt-Hess grades IV to $\mathrm{V}$ had higher ACTH concentrations at days one $(10.7 \pm 7.1 \mathrm{pmol} / \mathrm{L})$ and five $(8.2 \pm 7.7 \mathrm{pmol} / \mathrm{L})$ than patients with Hunt-Hess grades I to III (day one:3.8 $\pm 2.0 \mathrm{pmol} / \mathrm{L}, \mathrm{p}=$ 0.002 ; day five: $4.7 \pm 1.8 \mathrm{pmol} / \mathrm{L}, \mathrm{p}=0.04)$. GCS $(<8$ or $>$ $8)$, Fisher grade [16] (I-II versus III-IV), or presence of hydrocephalus did not affect ACTH concentrations.
Figure 5 illustrates the response to exogenous ACTH (ACTH stimulation test). At day one, eight (33\%) patients with $\mathrm{SAH}$ and eight $(50 \%)$ control patients had a cortisol response less than $248 \mathrm{nmol} / \mathrm{L}(\mathrm{p}=0.11)$. At day five and at three months, one patient with $\mathrm{SAH}$ and no control patients had a cortisol response less than $248 \mathrm{nmol} / \mathrm{L}$ (neither was significant). The patient with a failed synachten test at three months also failed the first and second test. The 24-hour urinary free cortisol concentration was $4896 \pm 5342 \mathrm{nmol} / \mathrm{L}$ in patients with $\mathrm{SAH}$ and $1641 \pm 1601 \mathrm{nmol} / \mathrm{L}$ in the control group at day two $(\mathrm{p}=$ 0.001 ). At day six, the urinary 24 -hour free cortisol concentration was $3276 \pm 3710 \mathrm{nmol} / \mathrm{L}$ in patients with $\mathrm{SAH}$. The evolution of CBG concentration is presented in Figure 6.

\section{Discussion}

According to our study, SAH causes an HPA axis response similar to that of elective cranial aneurysm surgery. The severity of SAH does not affect serum free or total cortisol concentrations, which could potentially reflect relative $\mathrm{Al}$ in patients with more severe $\mathrm{SAH}$. We also found a good correlation between serum free and total cortisol concentrations; therefore calculation of serum free cortisol may not offer any advantage in the clinical setting.

One of the major stress responses to trauma is the activation of the HPA axis to increase cortisol production. SAH may disturb the function of the HPA axis by brain swelling, microinfarctions, venous stasis, surgical manipulation or hypoperfusion of the brain [8]. Some data suggest delayed insufficiency of the HPA axis after SAH $[5,17,18]$. Little is known of the cortisolsecretion dynamics in the very acute phase in SAH or about the function of the whole HPA axis over time in patients with $\mathrm{SAH}$. Studies in acute neurosurgical patients include only a very few patients with $\mathrm{SAH}$ and predominantly patients with TBI $[19,20]$. Additionally, some patients in previous studies had received glucocorticoid treatment [21]or only a single time point was investigated [19]. However, we could not demonstrate any difference in the behaviour of serum total cortisol concentrations between patients with $\mathrm{SAH}$ and patients in the control group. Furthermore, although open aneurysm surgery was supposed to cause a clearer elevation of serum cortisol concentrations than endovascular treatment, we did not observe any difference in the HPA function between patients with surgical and endovascular treatment of their ruptured aneurysms. Neither were we able to show any difference in the adrenal response between comatose (GCS $<8$ ) and noncomatose patients. This indicates that adrenal response may be inadequate, that is it may be insufficient in the comatose and therefore more severely ill patients.

We are not aware of other studies that provide calculation of serum free cortisol concentration in patients with $\mathrm{SAH}$. Cortisol is bound about $90 \%$ to CBG and albumin, and only the unbound free fraction is responsible for the physiological effects. By measuring CBG, it is possible to obtain the serum 

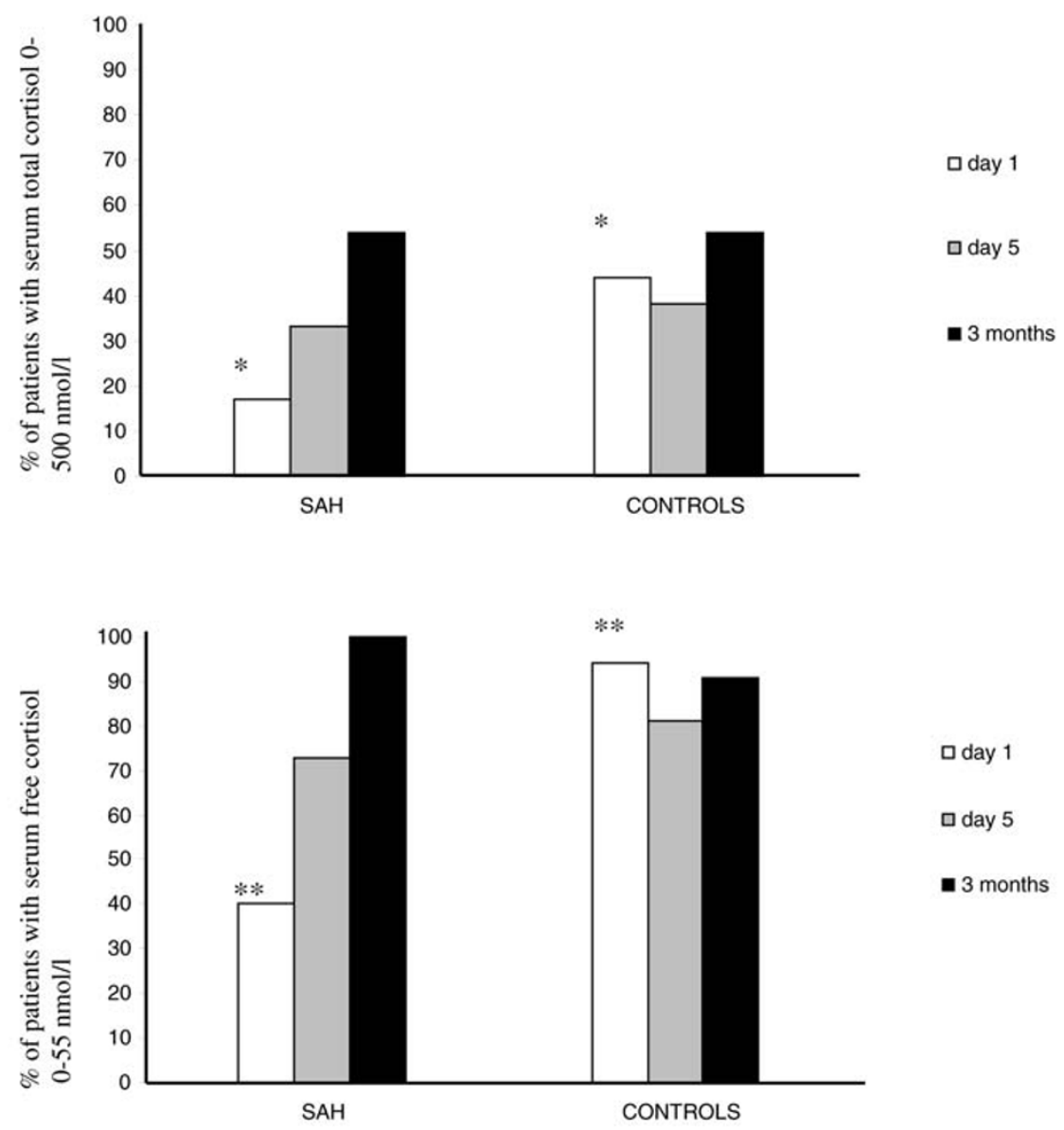

Percentage of patients with baseline serum free cortisol concentration less than $55 \mathrm{nmol} / \mathrm{L}$ or serum total cortisol concentration less than $500 \mathrm{nmol} / \mathrm{L}$. ${ }^{*}=$ difference between the groups at day one, $p=0.046 .{ }^{* *}=$ difference between the groups at day one, $p<0.001$.

free cortisol concentration using the Coolens' method [9] which has been shown to be reliable in ICU patients [22]. CBG has a low capacity and high affinity for cortisol and it becomes saturated at a serum cortisol concentration of about $690 \mathrm{nmol} / \mathrm{L}$ [11]. This is seen in Figure 3 as a change in the slope of the correlation lines. Any alterations in plasma albumin and $\mathrm{CBG}$ concentration may affect the relationship between serum free and total cortisol concentrations; however, this is not seen in Figure 3 as the majority of the data follow a similar trend. This is to be expected as CBG concentrations are not grossly affected in SAH (Figure 6).

It has also been suggested that serum albumin may affect testing of adrenal function in critically ill patients [12]. We found that calculation of serum free cortisol concentration was not more informative than measurement of serum total cortisol concentrations. Furthermore, we did not see any difference in serum free or total cortisol concentrations in hypoalbumenic versus other patients. Neither did we observe any difference in
CBG concentration in hypoalbumenic patients as compared with patients with an albumin concentration more than $25 \mathrm{~g} / \mathrm{L}$. This finding is in accordance with those of a previous study by Ho and colleagues in which they found that adjustment of the Coolens' equation constant to albumin concentration had only a minimal effect on estimated serum free cortisol [22].

ACTH concentrations were higher in patients with Hunt-Hess grades IV to V compared with patients with Hunt-Hess grades I to III. It remains unclear if the ACTH response is sufficient or if the adrenal gland responds adequately to ACTH. The adrenal gland response is likely to be unaffected because the cortisol response to exogenous ACTH was adequate. It is possible that $\mathrm{SAH}$ already causes $\mathrm{ACTH}$ deficiency and secondary $\mathrm{Al}$ in the acute phase of bleeding and some studies suggest that this may last years after the primary ictus present $[5,17]$. As an indication of this, we found patients with $\mathrm{SAH}$ who had low serum free or total cortisol concentrations and low ACTH concentrations reflecting possible secondary Al. 
ACHT test 1

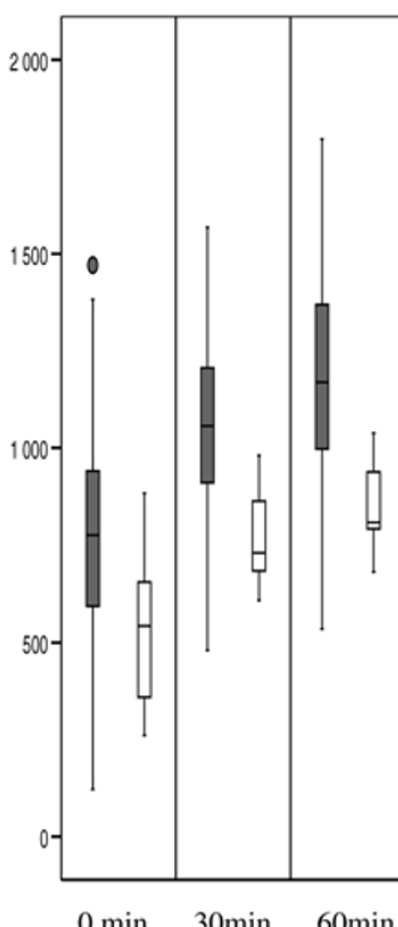

$=$ patients with $\mathrm{SAH}$

$=$ control patients
ACTH test 2

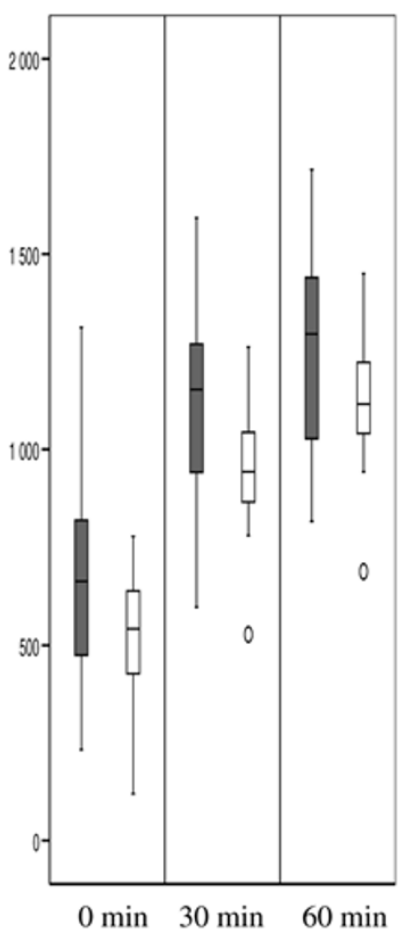

ACTH test 3

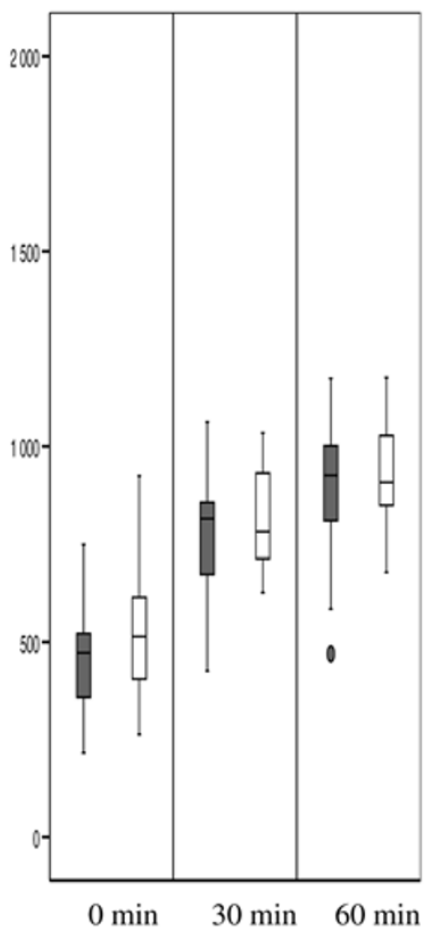

Response to exogenous adrenocorticotropic hormone (ACTH) in patients with subarachnoid haemorrhage (SAH) and control patients. There were no statistically significant differences between the groups. The percentage of patients with a serum cortisol response less than 248 $\mathrm{nmol} / \mathrm{L}$ also was not different between the groups. Test one $=$ day one; test two $=$ day five (control) and day seven $(\mathrm{SAH}) ;$ test three $=$ three months. Data are presented as median, interquartile ranges and outliers.

We found no correlation between serum ACTH concentration and serum free or total cortisol concentrations. This finding is not in accordance with that of Tanriverdi and colleagues [23] who identified a correlation between serum cortisol and ACTH concentration with measures at a single time point only. It must be remembered that in stress situations there is also nonACTH-mediated cortisol secretion caused by inflammatory cytokines for example [24]. Medication of the patients may affect cortisol secretion as well [3]. Patients in the present study did not receive any etomidate.

Critically ill patients who have relative adrenal insufficiency confirmed by the ACTH-stimulation test may benefit from cortisol-substitution therapy [25]. We observed similar incidences of adrenal insufficiency in both the patients with $\mathrm{SAH}$ and the control group when the ACTH-stimulation test was performed repeatedly. In critically ill patients, the value of
ACTH testing has recently been questioned [26], especially the value of this test in detecting $\mathrm{Al}$ at high baseline cortisol concentration which might tell us of an exhausted adrenal gland rather than real adrenal insufficiency. This test may not be reliable for detecting adrenal insufficiency in critically ill patients, and confounding factors influence the method by which cortisol is analysed [27,28]. Despite our efforts, it remains unclear whether the HPA axis response in patients with $\mathrm{SAH}$ is adequate.

There are several different classifications and diagnostic criteria for detecting $\mathrm{Al}$ and they differ in sensitivity and specificity [29]. These criteria are based either on random serum total cortisol concentration $[10,30]$ or on the ACTH-stimulation test [13]. Depending on the criteria used, the incidence of Al varies widely, as it does, for example, in patients with TBI [4]. It is noteworthy, however, that the diagnostic criteria have been 
Figure 6

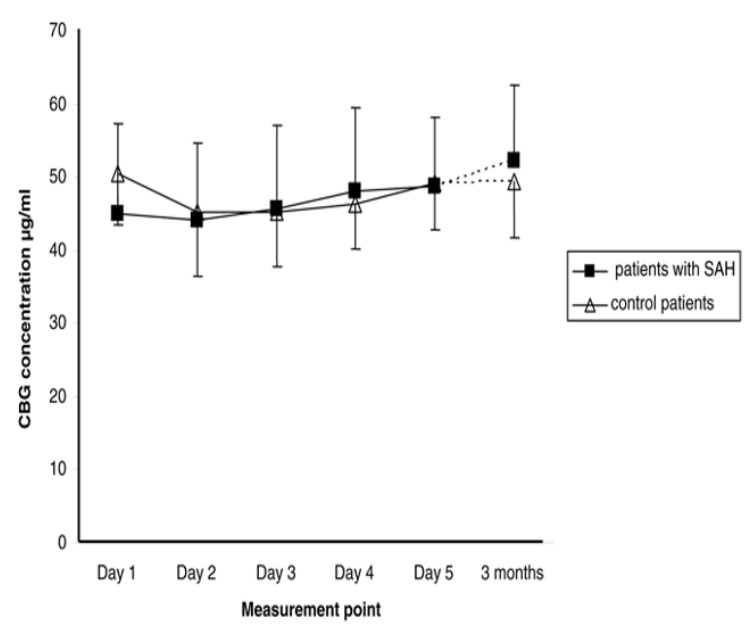

Evolution of corticoid-binding globulin (CBG) concentration in patients with subarachnoid haemorrhage (SAH) and control patients. There were no between-group differences, but CBG concentration changed significantly over time in both groups, $p=0.008$. Data are presented as mean \pm standard deviation.

derived from studies on patients who do not have acute intracranial pathology. Specifically, there are no studies that focus on the acute phase of SAH. Hence, the definitions for HPA axis deficiency are not available for these patients. In our study, the incidence of adrenal insufficiency in SAH varied between $17 \%$ and $50 \%$ depending on the different existing definitions used for critically ill patients in general. In this respect, we did not find any difference in $\mathrm{Al}$ between patients with $\mathrm{SAH}$ or control patients. Despite recent suggestions, our findings indicate that it is premature to recommend glucocorticoid treatment for patients with SAH [8]. For example, we found much higher 24-hour urinary free cortisol concentrations in patients with SAH compared with control patients, which could support an assumption of the presence of adequate cortisol dynamics.

There are some limitations in our study. Although we used versatile methods to investigate the HPA axis response over time, we could not evaluate the period between one week and three months. To choose another control group, for example septic or trauma patients, would have caused numerous additional confounding factors including corticoid therapy, infections and repeated operations. We were also unable to recruit as many patients into the control group as we originally planned. Our study was not powered for subgroup analysis. In addition, the number of patients with severe bleeding was limited, which could potentially have affected our results.

\section{Conclusions}

For the first time the function of the HPA axis in patients with acute $\mathrm{SAH}$ was characterised over time, up to three months, using various methods. Our findings suggest that $\mathrm{SAH}$ causes a rapid cortisol response, but whether this response is adequate in more severely ill patients remains unclear. The clinical picture of our patients does not support $\mathrm{Al}$ in patients with $\mathrm{SAH}$. Calculation of serum free cortisol concentrations does not seem to be helpful in assessing adrenal function in patients with $\mathrm{SAH}$.

\section{Key messages}

- This is the first study to investigate adrenal function in patients with clearly defined acute aneurysmal SAH

- Severe SAH causes various rises in cortisol and ACTH; some patients have values that could be inappropriate for the amount of stress sustained

- Calculation of serum free cortisol is not helpful in assessing adrenal function in SAH

- More studies are needed to define normal HPA response in acute SAH

\section{Competing interests}

This study was supported in part, by academic grants from Maire Taponen Foundation, Helsinki, Finland and Kuopio University Hospital Grant, Kuopio, Finland. The authors declare that they have no competing interests.

\section{Authors' contributions}

SB, AU and TK participated in study conception, acquisition of data, analysis and interpretation of data, drafting the manuscript and critically revising it. ER participated in study conception, analysis and interpretation of data, drafting the manuscript and critically revising it. JRI and IV participated in study conception, manuscript drafting and critically revising it. JRO participated in analysis and interpretation of data, drafting the manuscript and critically revising it. VK participated in analysis and interpretation of data and in revising the critically manuscript.

\section{References}

1. Agha A, Phillips J, O'Kelly P, Tormey W, Thompson CJ: The natural history of post-traumatic hypopituitarism: Implications for assessment and treatment. Am J Med 2005, 118:1416.

2. Agha A, Rogers B, Mylotte D, Taleb F, Tormey W, Phillips J, Thompson CJ: Neuroendocrine dysfunction in the acute phase of traumatic brain injury. Clin Endocrinol (Oxf) 2004 , 60:584-591.

3. Cohan P, Wang C, McArthur DL, Cook SW, Dusick JR, Armin B, Swerdloff R, Vespa P, Muizelaar JP, Cryer HG, Christenson PD, Kelly DF: Acute secondary adrenal insufficiency after traumatic brain injury: A prospective study. Crit Care Med 2005, 33:2358-2366. 
4. Bernard F, Outtrim J, Menon DK, Matta BF: Incidence of adrenal insufficiency after severe traumatic brain injury varies according to definition used: Clinical implications. Br J Anaesth 2006, 96:72-76.

5. Dimopoulou I, Kouyialis AT, Tzanella M, Armaganidis A, Thalassinos N, Sakas DE, Tsagarakis S: High incidence of neuroendocrine dysfunction in long-term survivors of aneurysmal subarachnoid hemorrhage. Stroke 2004, 35:2884-2889.

6. Kreitschmann-Andermahr I, Hoff C, Niggemeier S, Pruemper S, Bruegmann M, Kunz D, Matern S, Gilsbach JM: Pituitary deficiency following aneurysmal subarachnoid haemorrhage. J Neurol Neurosurg Psychiatry 2003, 74:1133-1135.

7. Aimaretti G, Ambrosio MR, Di Somma C, Fusco A, Cannavo S, Gasperi M, Scaroni C, De Marinis L, Benvenga S, degli Uberti EC, Lombardi G, Mantero F, Martino E, Giordano G, Ghigo E: Traumatic brain injury and subarachnoid haemorrhage are conditions at high risk for hypopituitarism: Screening study at 3 months after the brain injury. Clin Endocrinol (Oxf) 2004, 61:320-326.

8. Schneider HJ, Kreitschmann-Andermahr I, Ghigo E, Stalla GK, Agha A: Hypothalamopituitary dysfunction following traumatic brain injury and aneurysmal subarachnoid hemorrhage: A systematic review. JAMA 2007, 298:1429-1438.

9. Coolens JL, Van Baelen H, Heyns W: Clinical use of unbound plasma cortisol as calculated from total cortisol and corticosteroid-binding globulin. J Steroid Biochem 1987, 26:197-202.

10. Marik PE, Zaloga GP: Adrenal insufficiency during septic shock. Crit Care Med 2003, 31:141-145.

11. Aron DC, Findling JW, Tyrrell JB: Glucocorticoids \& adrenal androgens. In Basic \& Clinical Endocrinology 8th edition. Edited by: Greenspan FS, Gardner DG. United States: Lange; 2007:346-389.

12. Hamrahian $\mathrm{AH}$, Oseni TS, Arafah $\mathrm{BM}$ : Measurements of serum free cortisol in critically ill patients. N Engl J Med 2004, 350:1629-1638.

13. Annane D, Sebille V, Troche G, Raphael JC, Gajdos P, Bellissant E: A 3-level prognostic classification in septic shock based on cortisol levels and cortisol response to corticotropin. JAMA 2000, 283:1038-1045.

14. Dimopoulou I, Tsagarakis S: Hypothalamic-pituitary dysfunction in critically ill patients with traumatic and nontraumatic brain injury. Intensive Care Med 2005, 31:1020-1028.

15. Hunt WE, Hess RM: Surgical risk as related to time of intervention in the repair of intracranial aneurysms. J Neurosurg 1968, 28:14-20.

16. Fisher CM, Kistler JP, Davis JM: Relation of cerebral vasospasm to subarachnoid hemorrhage visualized by computerized tomographic scanning. Neurosurgery 1980, 6:1-9.

17. Dimopoulou I, Tsagarakis S, Douka E, Kouyialis AT, Dafni U, Thalassinos N, Roussos C: The low-dose corticotropin stimulation test in acute traumatic and non-traumatic brain injury: Incidence of hypo-responsiveness and relationship to outcome. Intensive Care Med 2004, 30:1216-1219.

18. Kreitschmann-Andermahr I Hoff C, Saller B, Niggemeier S, Pruemper S, Hutter BO, Rohde V, Gressner A, Matern S, Gilsbach JM: Prevalence of pituitary deficiency in patients after aneurysmal subarachnoid hemorrhage. J Clin Endocrinol Metab 2004, 89:4986-4992.

19. Savaridas T, Andrews PJ, Harris B: Cortisol dynamics following acute severe brain injury. Intensive Care Med 2004, 30:1479-1483

20. Kelly DF, Gonzalo IT, Cohan P, Berman N, Swerdloff R, Wang C: Hypopituitarism following traumatic brain injury and aneurysmal subarachnoid hemorrhage: a preliminary report. $J$ Neurosurg 2000, 93:743-752.

21. Espiner EA, Leikis R, Ferch RD, MacFarlane MR, Bonkowski JA, Frampton CM, Richards AM: The neuro-cardio-endocrine response to acute subarachnoid haemorrhage. Clin Endocrinol (Oxf) 2002, 56:629-635.

22. Ho JT, Al-Musalhi H, Chapman MJ, MacFarlane MR, Bonkowski JA, Frampton CM, Richards AM: Septic shock and sepsis: a comparison of total and free plasma cortisol levels. J Clin Endocrinol Metab 2006, 91:105-114.

23. Tanriverdi F, Dagli AT, Karaca Z, Unluhizarci K, Selcuklu A, Casanueva FF, Kelestimur F: High risk of pituitary dysfunction due to aneurysmal subarachnoid haemorrhage: a prospective investigation of anterior pituitary function in the acute phase and 12 months after the event. Clin Endocrinol (Oxf) 2007, 67:931-937.

24. Chrousos GP: The hypothalamic-pituitary-adrenal axis and immune-mediated inflammation. N Engl J Med 1995, 332:1351-1362.

25. Annane D, Sebille V, Charpentier C, Bollaert PE, Francois B, Korach JM, Capellier G, Cohen Y, Azoulay E, Troche G, ChaumetRiffaut $P$, Bellissant $E$ : Effect of treatment with low doses of hydrocortisone and fludrocortisone on mortality in patients with septic shock. JAMA 2002, 288:862-871.

26. Sprung CL, Annane D, Keh D, Moreno R, Singer M, Freivogel K, Weiss YG, Benbenishty J, Kalenka A, Forst H, Laterre PF, Reinhart $\mathrm{K}$, Cuthbertson $\mathrm{BH}$, Payen D, Briegel J: Hydrocortisone therapy for patients with septic shock. N Engl J Med 2008, 358:111-124

27. Klose M, Lange M, Rasmussen AK, Hilsted L, Haug E, Andersen $M$, Feldt-Rasmussen $U$ : Factors influencing the adrenocorticotropin test: role of contemporary cortisol assays, body composition, and oral contraceptive agents. J Clin Endocrinol Metab 2007, 92:1326-1333.

28. Cohen J, Ward G, Prins J, Jones M, Venkatesh B: Variability of cortisol assays can confound the diagnosis of adrenal insufficiency in the critically ill population. Intensive Care Med 2006, 32:1901-1905.

29. Dorin RI, Qualls CR, Crapo LM: Diagnosis of adrenal insufficiency. Ann Intern Med 2003, 139:194-204.

30. Cooper MS, Stewart PM: Corticosteroid insufficiency in acutely ill patients. N Engl J Med 2003, 348:727-734. 